\title{
Uniaxial Compression Mechanical Properties of Rock Samples in Soft and Hard Composite Strata
}

\author{
Bo Wu $(\mathbb{D})$ and Wei Huang $(\mathbb{D}$ \\ College of Civil Engineering and Architecture, Guangxi University, Nanning, Guangxi 530004, China \\ Correspondence should be addressed to Wei Huang; wei.huang@st.gxu.edu.cn
}

Received 2 April 2020; Revised 18 May 2020; Accepted 3 June 2020; Published 23 June 2020

Academic Editor: Michelina Catauro

Copyright ( $\odot 2020$ Bo Wu and Wei Huang. This is an open access article distributed under the Creative Commons Attribution License, which permits unrestricted use, distribution, and reproduction in any medium, provided the original work is properly cited.

\begin{abstract}
In the upper soft and lower hard composite strata, it is very difficult to sample the rock and test the mechanical properties of the samples. The study of the mechanical properties of similar material samples by artificial manufacture may enable an alternative method to solve this problem. Therefore, the feasibility of artificial sample preparation and the test of mechanical properties of rock samples in the composite strata become the key to solve the study of mechanical properties of the upper soft strata and the lower hard composite strata. For this purpose, the artificial composite samples composed of two kinds of materials with different strengths were prepared by using cement and kaolin as similar materials. Through the uniaxial compression test of artificial composite rock samples, the effects of the strength ratio of similar materials and the thickness ratio of higher strength materials on the mechanical properties of composite specimens were analyzed. The results of uniaxial compression test show that artificial similar materials could be used to simulate the composite rock samples which are difficult to sample. Without considering the structural interface effect, the greater the strength ratio of similar materials, the greater the impact on the overall strength of composite specimens. The change of volume proportion of high-strength materials has a significant impact on the overall strength of composite specimens. Moreover, the numerical simulation and the experimental stress-strain curves both show a similar trend, indicating that the deformation of the composite strata mainly occurs in the soft part. The research results can provide reference for the test and analysis of mechanical properties in similar complex strata with difficult sampling.
\end{abstract}

\section{Introduction}

With the development of underground engineering, the upper soft and lower hard composite strata will inevitably be encountered [1-5]. This kind of stratum is often caused by geological movement and different degrees of weathering. The upper part is the weak stratum with higher weathering degree, and the lower part is the hard stratum with lower weathering degree [6]. When the underground engineering is built in this kind of composite stratum, it will cause engineering disasters such as uneven stress of surrounding rock collapse due to improper construction measures or other potential risks [1].

The research on composite strata mainly focuses on the construction of tunnels [2, 7-10] and coal mining [11-13]. There are many research studies on tunnel mechanics and tunnel excavation deformation control in the composite stratum. Due to the influence of mechanical properties of composite formation, the construction of large-span stations in the upper soft and lower hard strata is often the focus of research [3-6]. However, it is difficult to obtain the computational parameters of the composite formation when conducting numerical calculation and analysis, which need to be obtained through rock mechanics tests. In addition, some scholars have discussed the construction of tunnels in the upper soft and lower hard strata and the stress and construction deformation of surrounding rock by model test [8]. Moreover, shield tunnels passing through hard and soft composite strata are similar. The stability analysis could be carried out through large-scale model tests $[7,14]$, but this method is so difficult and uneconomical. Therefore, it is the most feasible and economic research method to obtain the mechanical properties of composite formation through rock mechanics test. 
In the existing research, it is found that it is very difficult to conduct composite stratigraphic sampling. Therefore, in the mechanical test of coal mining, the study of composite coal seam adopts the method of manual sample preparation, and the main purpose is to make coal-rock composite specimens to study their mechanical properties. The lower part of the sample is coal, representing the weak part; the upper part is the rock, representing the top $[11-13,15]$. Furthermore, the contact zone of the composite rock mass is also studied. Through the compression test, it is found that the mechanical properties of the rock mass in the contact zone are reduced, and the plastic area of the surrounding rock of the roadway in the contact zone increases under the condition of compression [9]. However, the composite stratum in the coal mining area is different from that in the general underground engineering. Therefore, the rule of composite formation in coal mining area cannot be directly applied to the construction of underground engineering, but this experimental research method can be adopted. Due to the difficulty of rock sampling in the upper soft and lower hard composite stratum, it could be found that there is no relevant rock sample test for the soft and hard strata in the surrounding rock of the tunnel. It is an effective method to study the mechanical properties of rock samples in the composite stratum by means of artificial sampling based on the mechanical properties' test method of composite stratum samples in the coal mining area. More and more, the method of acoustic emission [16] combined with the traditional uniaxial compression test $[17,18]$ could help to obtain more data which are beneficial for the evaluation of mechanical properties.

In this paper, the mechanical properties of the composite rock mass in soft and hard composite strata are studied. Cement and kaolin are used as the similar materials to make composite specimens composed of two different strength materials. The influence of the strength ratio of similar materials and the thickness ratio of higher strength materials on the mechanical properties of composite specimens is studied by the uniaxial compression test. In addition, the experiment results were compared by FLAC3D numerical simulation.

\section{Materials and Methods}

2.1. Experimental Scheme. In this experiment, the mechanical properties of composite strata under different soft-hard layer ratios are discussed. Taking the thickness of the soft and hard layers as the variable, it could be divided into five types: soft rock: hard rock-1:0,1:3, $1: 1,3: 1$, and $0: 1$, that is, according to the volume proportion of high-strength materials, $0 \%, 25 \%, 50 \%, 75 \%$, and $100 \%$ sample preparation. It is difficult to make natural and complete composite stratum samples. This time, artificial physical simulation samples are used instead of natural rock samples. The simulation samples are homogeneous and could be regarded as isotropic objects.

2.2. Sample Preparation. In order to reflect the strength difference of similar materials and the convenience of experimental operation, 32.5 mesh cement and 4000 mesh pure white kaolin were selected as raw materials to prepare specimens. The strength difference is reflected by changing the ratio of raw materials. $90 \%$ cement and $10 \%$ kaolin are regarded as hard rock samples. Cement and kaolin each accounting for $50 \%$ can be regarded as soft rock samples. The difference between the soft and hard parts of the artificial samples is not defined by absolute strength as the traditional sample. It is considered that the uniaxial compressive strength of the hard rock is more than 1 time of that of the soft rock, so the soft rock and hard rock could be distinguished. The composition and proportion of the soft rock and hard rock are shown in Table 1.

The composite sample is made by the direct pouring method, and the soft-hard interface is naturally coupled. Based on the production of a single test piece, different soft and hard materials are combined together. Two kinds of strength materials are in horizontal contact (the contact angle is $0^{\circ}$ ). As shown in Figure 1, S represents the lower strength material, which is used to represent the weak rock stratum; $\mathrm{H}$ represents the higher strength material, which is used to represent the hard rock stratum, and the coupling mode between the two materials is natural cementation.

The dimension of specimens is $50 \mathrm{~mm} \times 100 \mathrm{~mm}, 15$ specimens in total (6 for single test piece and 9 for composite test piece). The samples were poured for 7 days before demoulding. The samples were cured for 28 days and then the double-end faces were polished. Finally, the samples were measured and numbered.

2.3. Testing System and Process. The testing system shown in Figure 2 includes a loading module and an acoustic emission (AE) module, and Figure 3 shows the photographs of the instruments. The test method is uniaxial compression plus acoustic emission test system.

The loading system is YAW4306 microcomputer-controlled electrohydraulic servo pressure machine, with a maximum load of $3,000 \mathrm{kN}$. The resolution of the testing force indication (FS) is $1 / 300,000$ with $\pm 1 \%$ relative error. The system could not only control the applied force or the displacement of the specimen but also carry out uniaxial compression, stretching, cyclic loading, and creep experiments. The experiment is controlled by displacement. The displacement range is $5.0 \mathrm{~mm}$, the displacement rate is $0.002 \mathrm{~mm} / \mathrm{s}$, and the displacement limit is $3.20 \mathrm{~mm}$.

The AE probe is symmetrically arranged and fixed on the sample, as shown in Figure 3(a), and then the sample is placed on the loading system. The axial displacement is adjusted by loading the gasket, and the horizontal displacement is adjusted by using the horizontal probe sensor. After the adjustment is qualified, the sample size information is input, and the AE parameters are calibrated and preloaded. After preloading, the AE test is carried out. After debugging, click the single axis operation button and acoustic emission data save button to carry out the experiment.

\section{Results and Discussion}

3.1. Reliability Verification of Similar Material Sample. Considering the limited amount of test data, it is necessary to verify the validity of the test results. Figure 4 shows the results of uniaxial compression test with a thickness ratio of $1: 1$ for 
TABLE 1: Composition of the soft rock and hard rock.

\begin{tabular}{lccc}
\hline & Cement (\%) & Kaolin (\%) & Water (\%) \\
\hline Soft rock & 60 & 1 & 30 \\
Hard rock & 33 & 33 & 34 \\
\hline
\end{tabular}

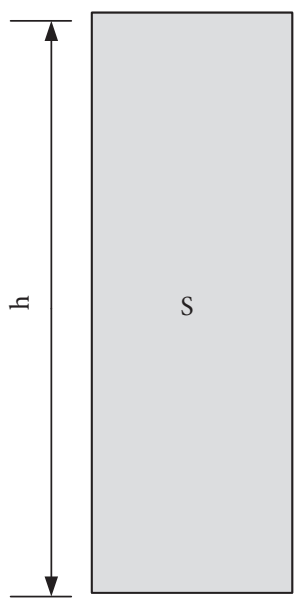

(a)

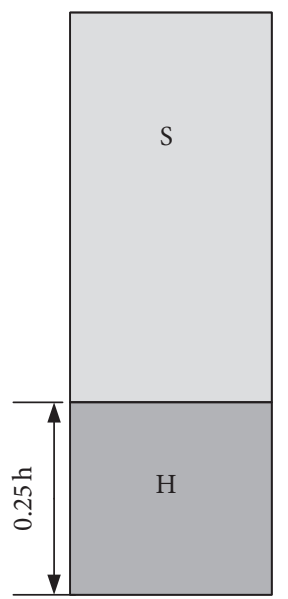

(b)

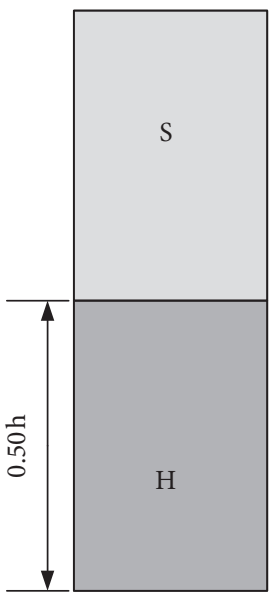

(c)

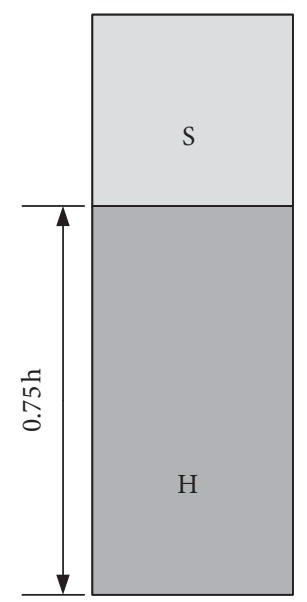

(d)

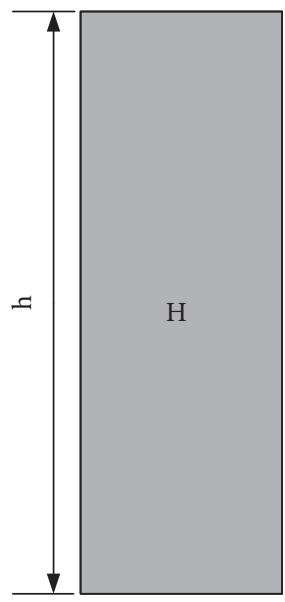

(e)

Figure 1: Sketch of the poured model of the composite specimen: (a) soft, (b) 25\% hard, (c) 50\% hard, (d) $75 \%$ hard, and (e) hard.
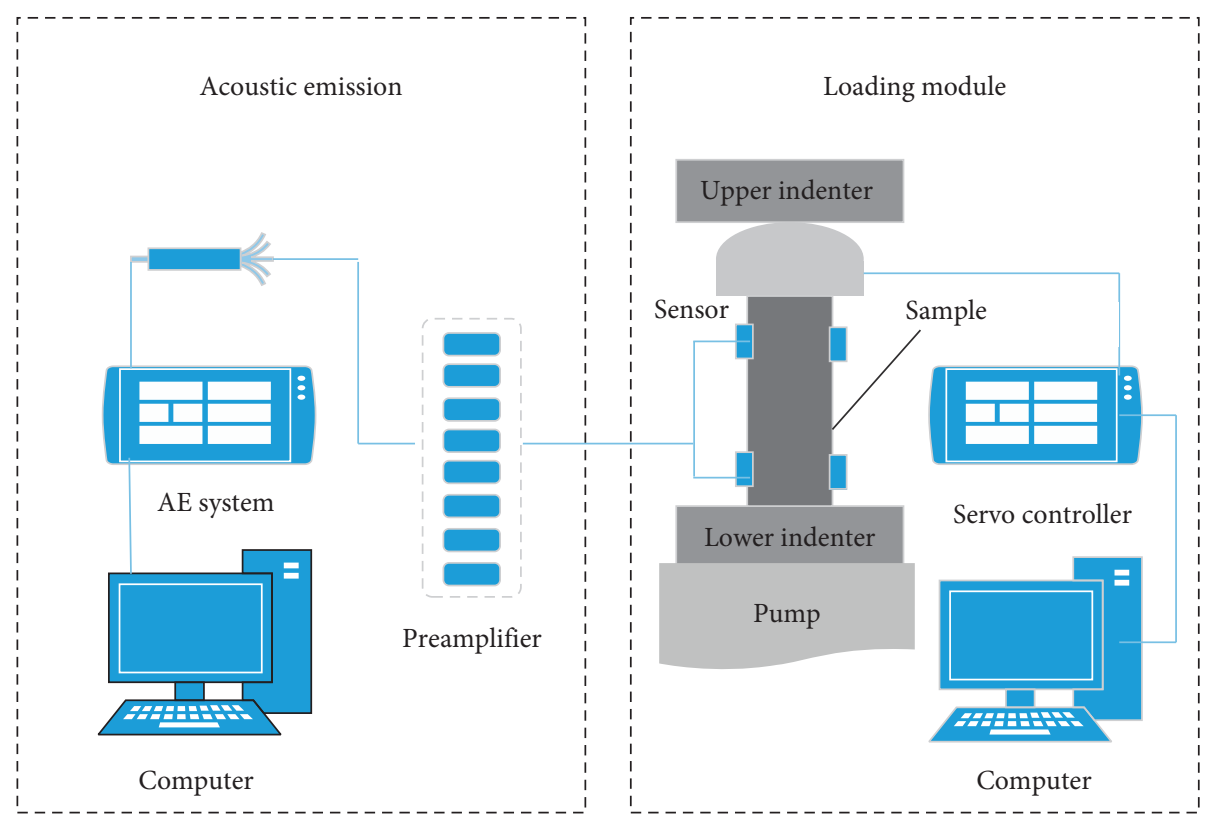

Figure 2: Sketch map of the testing system.

composite rock samples. It could be seen from Figure 4 that the strength and elastic modulus of the hard rock are the highest, followed by soft and hard composite layers, and finally the soft rock. The higher the strength is, the more obvious the brittleness is. In addition, the results of uniaxial compression also show that the composite formation made in this study meets the requirements. The greater the strength difference between the soft rock and hard rock in the actual project, the higher the difficulty of project construction. In order to get closer to the real composite stratum, the strength difference between the soft rock and hard rock selected in the study should be at least twice. The strength of the hard rock in the physical simulation sample is more than 2 times that of the soft rock, which meets the requirements.

3.2. Effect of Thickness Ratio on Mechanical Properties of Specimens. The thickness ratio of high-strength materials in two kinds of composite materials is $25 \%, 50 \%$, and $75 \%$, respectively. Considering the thickness ratio of two kinds of single 


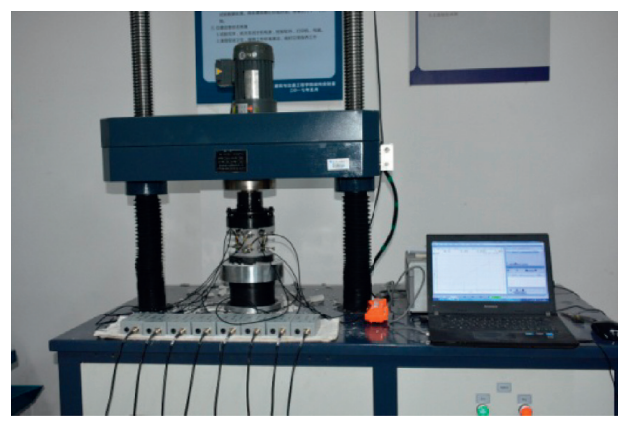

(a)

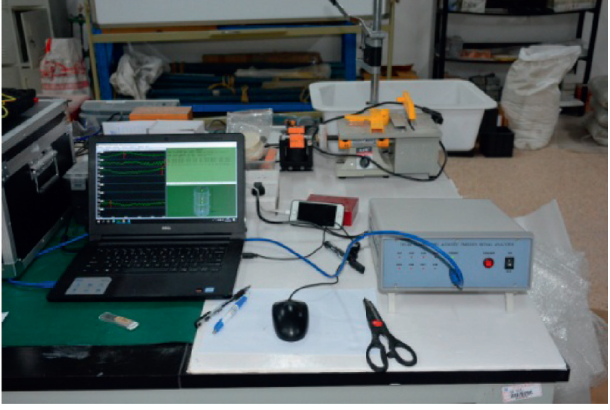

(b)

Figure 3: Physical experiment system diagram: (a) loading module and (b) acoustic emission (AE) module.

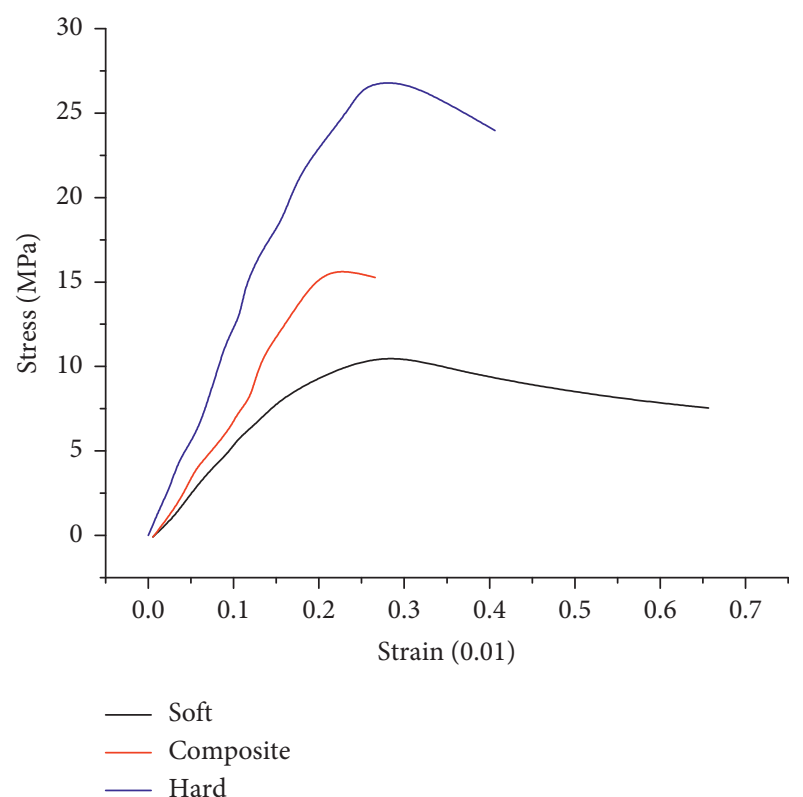

FIgURE 4: Axial stress-strain curves of uniaxial compression.

rock samples, i.e., $0 \%$ and $100 \%$, three tests were carried out in each group, and the average value of the test results was taken.

As shown from Figures 5-7, without considering the structural interface effect, the strength and modulus of elasticity of composite specimens increase with the increase of volume proportion of higher strength materials; Poisson's ratio of composite specimens increases at first, then decreases with the increase of volume proportion of higher strength materials, then increases, and then decreases, showing an M-type change. It could be seen that when the strength ratio of similar materials is fixed, the change of thickness ratio of higher strength materials has a significant effect on the strength of composite specimens.

In Figure 5, when the thickness is small, the strength of the composite specimen increases approximately, exponentially, and linearly. However, when the thickness exceeds $80 \%$, the slope of the curve becomes smaller, so the strength growth

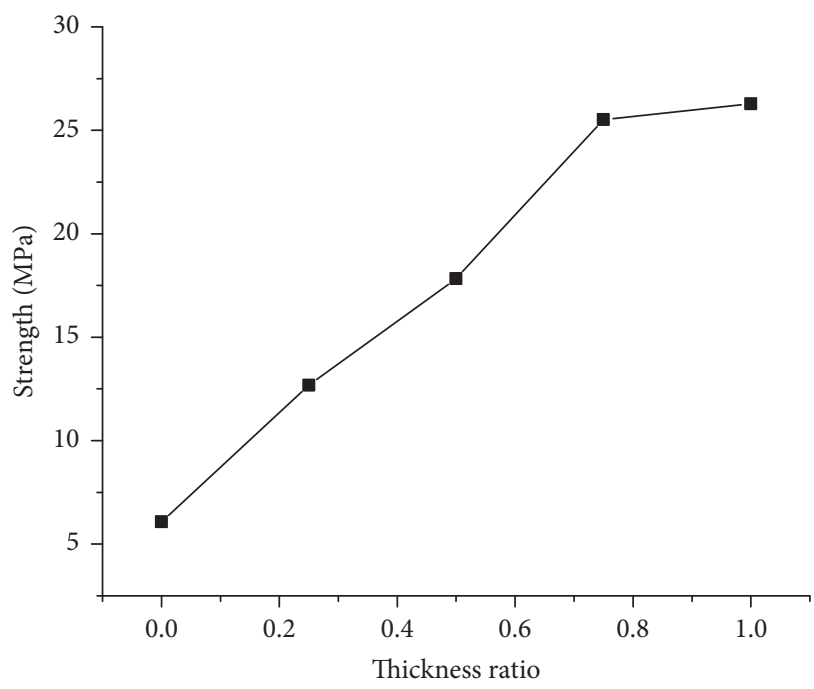

Figure 5: The influence of the thickness ratio of higher strength materials on the strength of specimens.

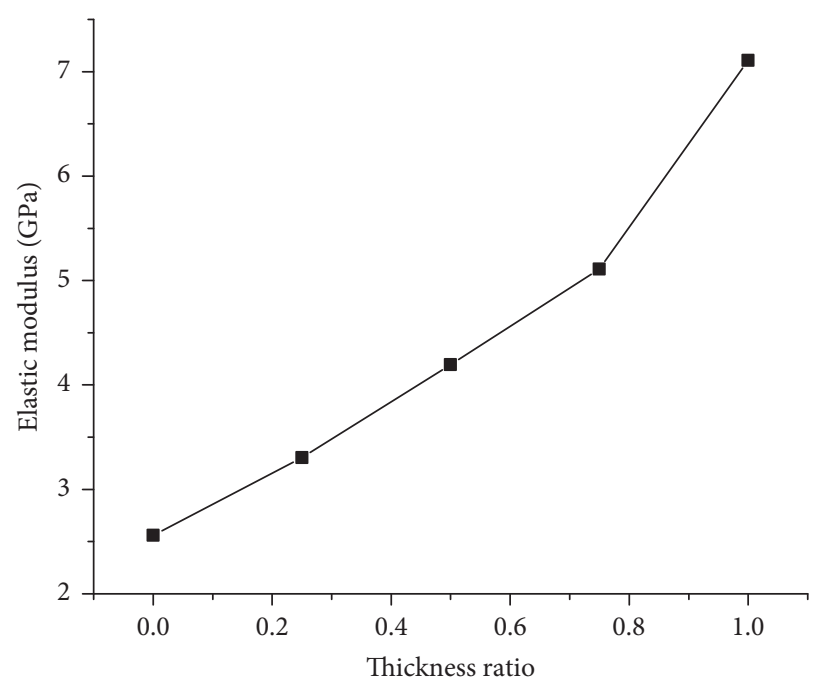

FIGURE 6: Effect of volume fraction of high-strength materials on the elastic modulus of specimens. 


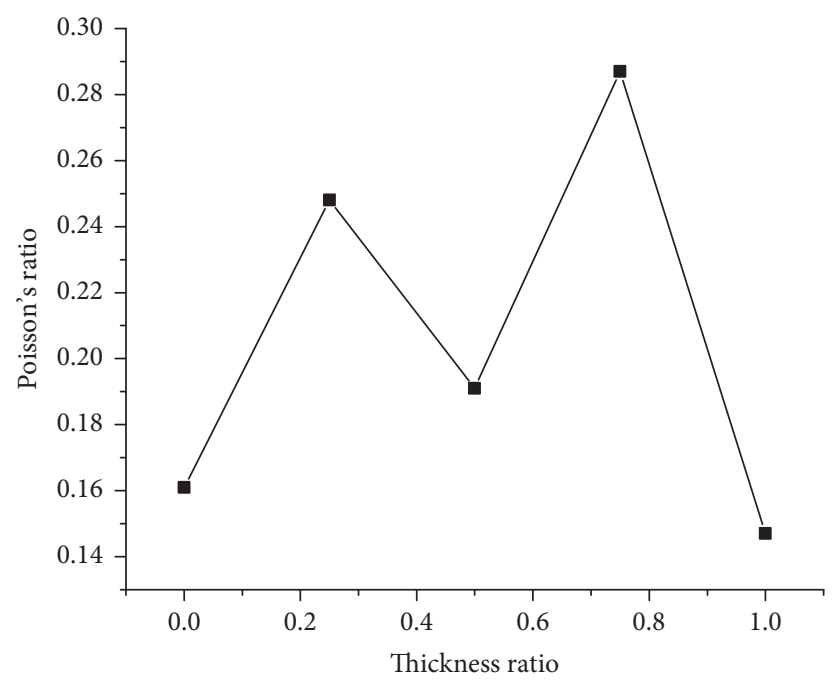

Figure 7: Effect of thickness ratio of high-strength materials on Poisson's ratio of specimens.

rate of the composite sample becomes correspondingly smaller. Therefore, when the thickness is small, the contribution of the hard part to the strength of the composite sample is relatively large, but when the thickness is small, the contribution of the hardness to the strength of the composite sample is decreasing.

In Figure 6, it can be found that the law of elastic modulus changing with thickness ratio is different from the law of strength changing with thickness ratio of the composite sample. When the thickness ratio exceeds $80 \%$, the slope of the curve becomes larger, and the elastic growth rate of the composite sample also increases correspondingly. Therefore, when the soft part accounts for a large proportion, the elastic modulus increases with the thickness ratio. When the hard part accounts for a large proportion, the elastic modulus increases rapidly.

Poisson's ratio reflects the mutual influence of material deformations in different directions. The pattern of Poisson's ratio changing with the thickness ratio is reflected in Figure 7. When the absolute proportion of a material is large, that is, when all samples are hard or all samples are soft, Poisson's ratio is smaller. As the proportion of the hard part increases, so does Poisson's ratio. However, when the proportion of soft and hard in the composite sample is half, that is, when the thickness ratio is $50 \%$, it is relatively small. This is related to the deformation and failure of the sample along the middle part of the sample. So, Poisson's ratio changes with the thickness ratio, and the curve shows an M-type change.

\subsection{The Acoustic Emission Characteristics of Composite} Specimens. In the process of uniaxial compression of the composite specimens, the acoustic emission phenomenon was monitored through eight channels in the upper and lower groups. Group $\mathrm{H}$ sensor was placed at the end of the higher strength material, and group $\mathrm{S}$ sensor was placed at the end of the lower strength material. Figure 8 shows the AE count and vertical stress distribution of different specimens at the same time. It could be seen from Figure 8 that the acoustic emission response of the specimen from the initial loading to the final failure is obvious, which corresponds to the change of stressstrain curve of the specimen under uniaxial loading.

As shown in Figure 8(a), when the soft rock is in the majority, the acoustic emission count of group $S$ is significantly higher than that of group $\mathrm{H}$; similarly, in Figure 8(b), when the soft rock and hard rock account for half of each other, the $\mathrm{AE}$ events of group $\mathrm{S}$ are significantly reduced, while those of group $\mathrm{H}$ are increased gradually; moreover, in Figure $8(\mathrm{c})$, when the hard rock is in the majority, the $\mathrm{AE}$ events of group $\mathrm{S}$ hardly occur, while the AE count of group $\mathrm{H}$ is more. Therefore, it could be seen that the AE count changes with composite specimens under uniaxial compression and the failure position and shape of specimens. With the increase of the hard rock content, the number of $\mathrm{AE}$ counts at the end of higher strength materials decreases, while that at the end of lower strength materials increases.

In addition, the mutation point of the $\mathrm{AE}$ count appeared slightly earlier than the stress mutation point of the sample. This phenomenon is mainly due to the loading specimen in the process of the internal pressure increasing continuously, and the energy accumulation and release reached a peak. The AE count firstly reached the peak, and internal damage speeded up after this peak. After that, the stress of the specimen reached a peak value of stress, but the AE counts would count down accordingly. As the sample undergoes internal damage, it is unable to stimulate more acoustic emission counts.

\section{Numerical Calculation}

In order to analyze the mechanical characteristics of composite strata with different thickness ratios of soft and hard layers, FLAC3D numerical software was used to analyze the mechanical behavior of composite strata based on the strain softening model of Mohr-Coulomb shear failure criterion. As shown in Table 2, it is used to simulate the mechanical parameters of the soft rock and hard rock. The parameters in Table 2 are taken according to the abovementioned uniaxial compression test results and 

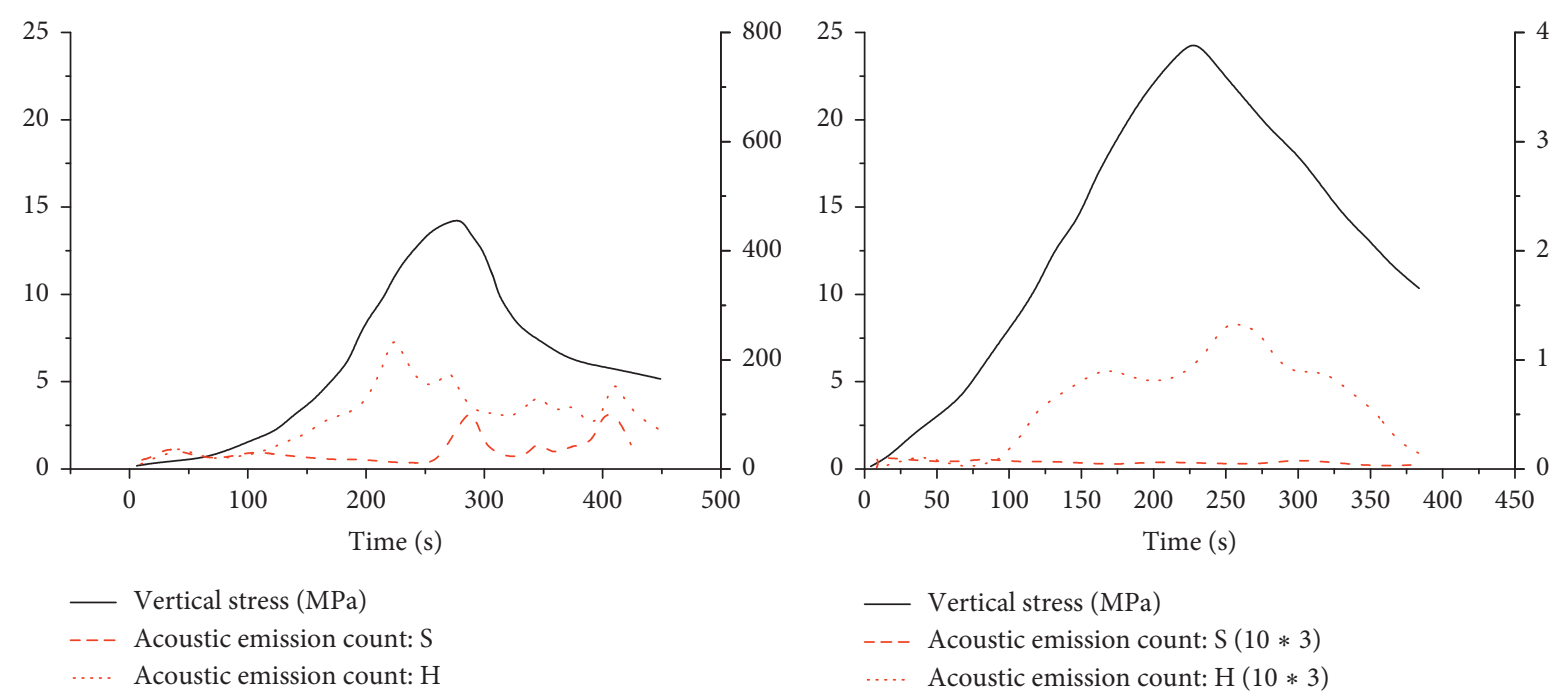

(a)

(b)

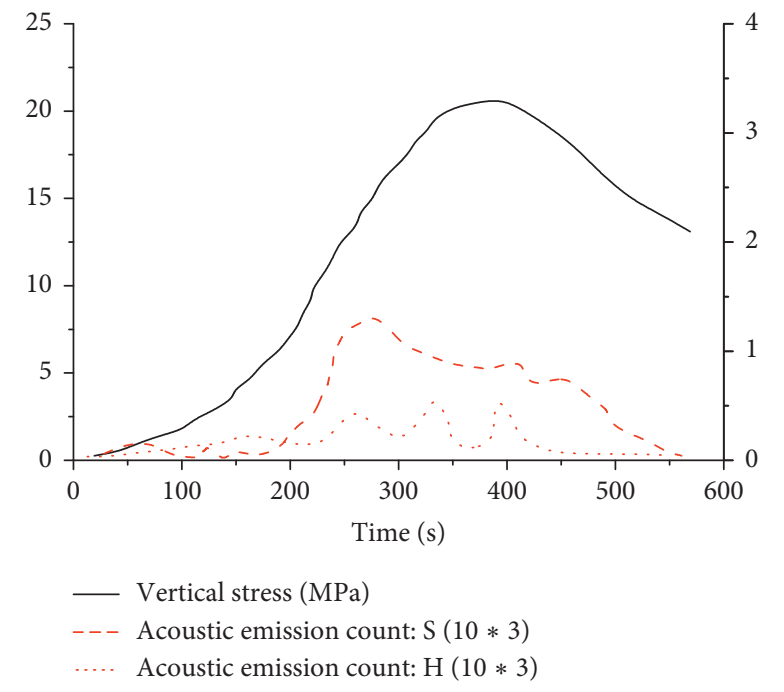

(c)

Figure 8: AE counts and vertical stress distributions. Thickness ratio: (a) 25\%, (b) 50\%, and (c) 75\%.

TABLE 2: Rock mass parameters of composite strata.

\begin{tabular}{lcccccc}
\hline & $\begin{array}{c}\text { Bulk modulus } \\
(\mathrm{GPa})\end{array}$ & $\begin{array}{c}\text { Shear modulus } \\
(\mathrm{GPa})\end{array}$ & $\begin{array}{c}\text { Cohesive force } \\
(\mathrm{MPa})\end{array}$ & $\begin{array}{c}\text { Friction angle } \\
\left({ }^{\circ}\right)\end{array}$ & $\begin{array}{c}\text { Tensile strength } \\
(\mathrm{MPa})\end{array}$ & $\begin{array}{c}\text { Dilation angles } \\
\left({ }^{\circ}\right)\end{array}$ \\
\hline $\begin{array}{l}\text { Soft rock } \\
\text { Hard }\end{array}$ & 1.15 & 1.00 & 4 & 20 & 1.00 & 10 \\
rock & 6.45 & 2.78 & 7 & 26 & 2.00 & 10 \\
\hline
\end{tabular}

previous literature results. Both uniaxial and triaxial compression tests adopt strain-controlled loading mode, with a strain rate of $0.02 \% / \mathrm{m}$, and a uniformly distributed load is applied vertically down the $Z$-axis on the top of the model.

The comparison of numerical simulation results and physical model test results of uniaxial compression mechanical test is shown in Table 3. It could be seen from the table that the uniaxial compressive strength and peak strain of the soft rock and hard rock are close to the aforementioned test results, which confirms the reliability of the simulation results and lays a foundation for the later triaxial compression simulation analysis.

The axial stress-strain curve and the maximum principal stress nephogram of FLAC3D numerical simulation are shown in Figures 9 and 10, respectively. Figure 9 shows the axial stress-strain curves of uniaxial compression with different thickness ratios. It could be seen from the figure that the mechanical properties of the composite stratum are 
TABLE 3: Comparison of the results of uniaxial compression between numerical calculation and physical simulation test.

\begin{tabular}{|c|c|c|c|c|}
\hline \multirow{2}{*}{ Thickness ratio (\%) } & \multicolumn{2}{|c|}{ Uniaxial compressive strength $(\mathrm{MPa})$} & \multicolumn{2}{|c|}{ Peak strain $\left(10^{-2}\right)$} \\
\hline & Calculated value & Test value & Calculated value & Test value \\
\hline 25 & 12.32 & 8.36 & 0.27 & 0.29 \\
\hline 50 & 13.85 & 16.9 & 0.2 & 0.24 \\
\hline 75 & 28.34 & 27.23 & 0.2 & 0.27 \\
\hline
\end{tabular}

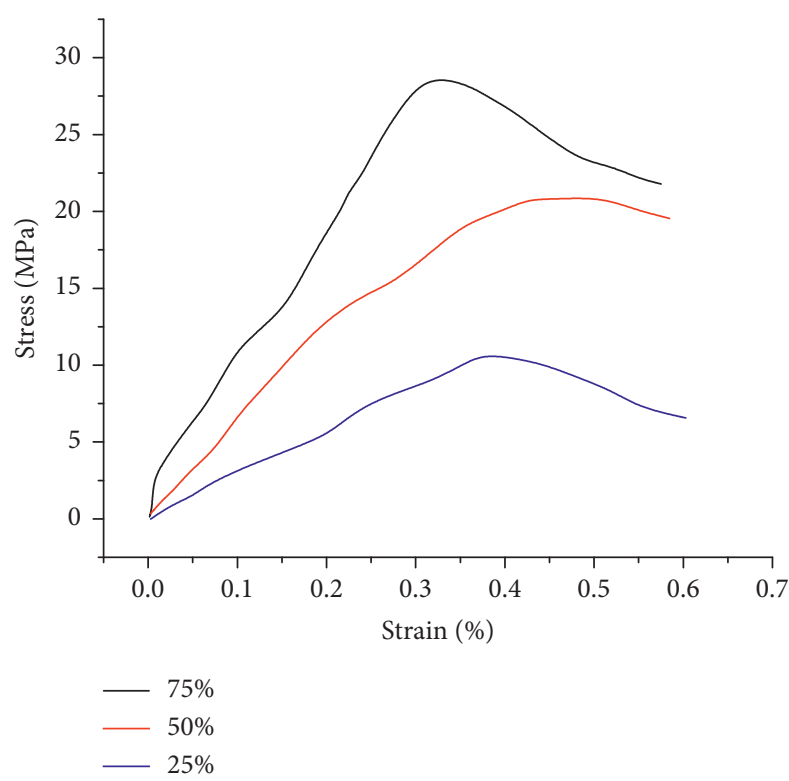

Figure 9: Numerical simulation of axial stress-strain curve with different thickness ratios.

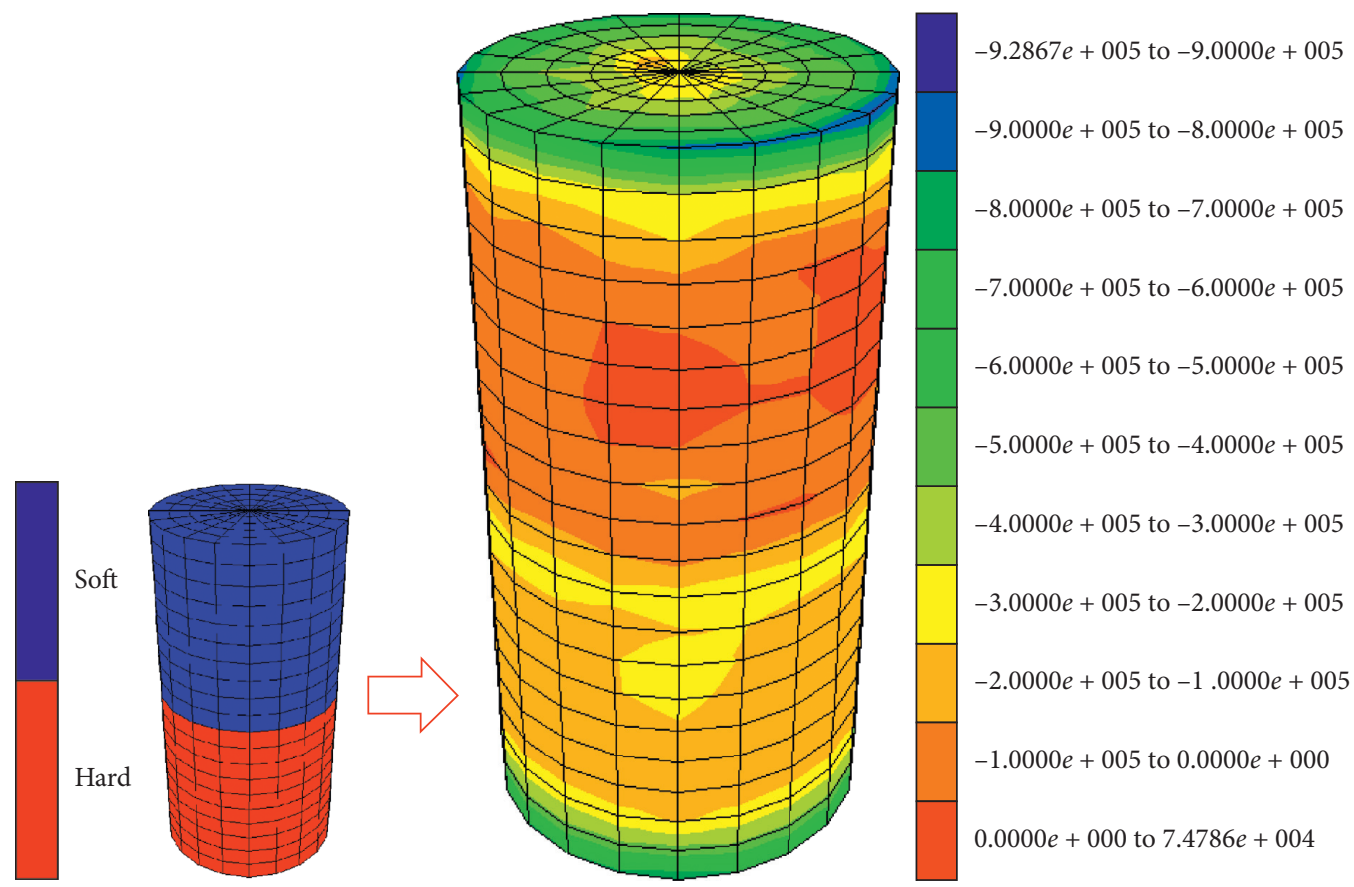

FIGURE 10: Nephogram of the maximum principal stress with a thickness ratio of $50 \%$. 
more controlled by lithology, which is consistent with the mechanical test results of the specimens.

From Figure 10, it shows the maximum principal stress nephogram of representative samples. It could be seen from Figure 10 that the deformation mainly occurs in the soft rock part, which is also consistent with the results of the mechanical test. Since the maximum principal stress could be regarded as the vector sum of the normal stress and the shear stress, the maximum principal stress is used to describe the actual stress on the sample, and its size determines whether the sample has cracks and suffers from shear failure. The value of the soft part is about double that of the hard part, and the failure occurs in the soft part first in the test, which is consistent with the test. Therefore, it is feasible to use this method to simulate similar composite rocks.

\section{Conclusions}

(1) When uniaxial compression occurs, the brittle tensile failure occurs in the composite stratum, and the strength is between the soft rock and hard rock. The strength of the hard rock is more than twice that of the soft rock, which indicates that the artificial composite formation could meet the requirements of strength difference.

(2) Uniaxial compression with different thickness ratios reveals that the mechanical properties of composite strata are determined by lithology, which accounts for the majority of composite strata without considering the structural plane and other factors.

(3) The composite specimen has obvious acoustic emission response characteristics from the initial loading to the final failure. With the increase of the strength ratio of similar materials, the end acoustic emission count of high-strength materials decreases gradually, and the end acoustic emission count of lower strength materials increases gradually. There is a corresponding relationship between the change of $\mathrm{AE}$ count and the failure position and shape of composite specimens.

(4) The simulation value of FLAC3D is close to the experimental value, which verifies the reliability of numerical simulation and supports the conclusion of the mechanical test. Both numerical simulation and physical experiments show that the deformation of composite stratum mainly occurs in the soft rock.

\section{Data Availability}

The datasets used and analyzed during the current study are available from the corresponding author on reasonable request.

\section{Conflicts of Interest}

The authors declare no conflicts of interest.

\section{Acknowledgments}

This research was funded by the National Science of China (51478118), the Guangxi Science and Technology Plan Projects (AD18126011), and the China Scholarship Council.

\section{References}

[1] B. Wu, "Study on vibration of tunnel blasting construction in upper soft and lower hard ground," IOP Conference Series: Earth and Environmental Science, vol. 242, Article ID 062004, 2019.

[2] J. Yan, X. Hu, and B. Liu, "Stability of shield tunnel excavation face in upper-soft and lower-hard composite strata," Tunnel Construction, vol. 40, no. 2, pp. 223-230, 2020.

[3] K. Sun, W. Xu, W. Qiu, H. Li, Q. Xian, and T. Li, "Study on the characteristics of safety distribution changing with buried depth for metro station in upper-soft and lower-hard stratum," Advances in Civil Engineering, vol. 2018, Article ID 6047919, 14 pages, 2018.

[4] Y. Shang, S. Du, T. Han, and B. Shao, "Case study on deformation control of upper-soft and lower-hard large span tunnel station using combined control Technology and monitoring demonstration," Sains Malaysiana, vol. 46, no. 11, pp. 2091-2099, 2017.

[5] J. Wang, "Study on adaptability of primary support arch cover method for large-span embedded tunnels in the upper-soft lower-hard stratum," Advances in Mechanical Engineering, vol. 11, no. 1, 2019.

[6] H. Tu, "Excavation and kinematic analysis of a shallow largespan tunnel in an up-soft/low-hard rock stratum," Tunnelling and Underground Space Technology, vol. 97, 2020.

[7] S.-Q. Yang, M. Chen, G. Fang et al., "Physical experiment and numerical modelling of tunnel excavation in slanted uppersoft and lower-hard strata," Tunnelling and Underground Space Technology, vol. 82, pp. 248-264, 2018.

[8] W. Wang, "Conversion timing of tunnel excavation methods in upper-soft and lower-hard stratum based on displacement direction angle theory: case study," International Journal of Geomechanics, vol. 19, no. 4, 2019.

[9] A. Yassaghi and H. Salari-Rad, "Squeezing rock conditions at an igneous contact zone in the Taloun tunnels, TehranShomal freeway, Iran: a case study," International Journal of Rock Mechanics and Mining Sciences, vol. 42, no. 1, pp. 95108, 2005.

[10] Y. Tang and J. Xu, "Shield tunneling in rock-soil interface composite formations," Geotechnical and Geological Engineering, vol. 34, no. 6, pp. 1693-1705, 2016.

[11] H. Zhang, Z. Wan, Y. Zhang, and D. Wu, "Mechanical properties and failure behavior of composite samples," Advances in Materials Science and Engineering, vol. 2018, Article ID 2545127, 16 pages, 2018.

[12] J. Liu, E. Wang, D. Song, S. Wang, and Y. Niu, "Effect of rock strength on failure mode and mechanical behavior of composite samples," Arabian Journal of Geosciences, vol. 8, no. 7, pp. 4527-4539, 2014.

[13] S. Chen, Y. Ge, D. Yin, and H. Yang, "An experimental study of the uniaxial failure behaviour of rock-coal composite samples with pre-existing cracks in the coal," Advances in Civil Engineering, vol. 2019, Article ID 8397598, 12 pages, 2019.

[14] S.-Q. Yang, "Large-scale model experiment and numerical simulation on convergence deformation of tunnel excavating in composite strata," Tunnelling and Underground Space Technology, vol. 94, 2019.

[15] H. Zhang, D. Elsworth, and Z. Wan, "Failure response of composite rock-coal samples," Geomechanics and Geophysics for Geo-Energy and Geo-Resources, vol. 4, no. 2, pp. 175-192, 2018.

[16] T. Qin, H. Sun, H. Liu et al., "Experimental study on mechanical and acoustic emission characteristics of rock samples 
under different stress paths," Shock and Vibration, vol. 2018, Article ID 4813724, 9 pages, 2018.

[17] M. Ji, K. Chen, and H. J. Guo, "Constitutive model of rock uniaxial damage based on rock strength statistics," Advances in Civil Engineering, vol. 2018, Article ID 5047834, 8 pages, 2018.

[18] R. Xu, "Influence of flaw inclination angle on cracking behavior of rock-like materials under uniaxial compression," Advances in Materials Science and Engineering, vol. 2019, Article ID 6942586, 10 pages, 2019. 